www.jmscr.igmpublication.org

Impact Factor (SJIF): 6.379

Index Copernicus Value: 79.54

ISSN (e)-2347-176x ISSN (p) 2455-0450

crossrefDOI: https://dx.doi.org/10.18535/jmscr/v6i10.188

Journal Of Medical Science And Clinical Research

\title{
Epidemiology and Clinical Presentations of Abdominal Tuberculosis
}

\author{
Authors \\ Dr A. Harish Kumar, Dr R. Baskaran, Dr K. Karthikraja, Dr M. Prema \\ Department of General Surgery, Rajah Muthiah Medical College \& Hospital, Chidambaram, India
}

\begin{abstract}
Background: Tuberculosis is one of the commonest communicable diseases to mankind. It has significant morbidity in India. Abdominal tuberculosis is difficult to diagnose and we should have high index of suspicion to diagnose it. This study aims to document Epidemiological profile and Clinical Presentations of Abdominal Tuberculosis.

Methods: This study was a Retrospective \& Prospective observational study of 50 cases which were diagnosed and treated as Abdominal Tuberculosis between August 2013-August 2018 in Rajah Muthiah Medical College, Chidambaram, Tamilnadu, India. All patients who were diagnosed with abdominal Tuberculosis, whether operated or not, were put on anti-tubercular drugs for a period of 6 months and regular follow up was made.
\end{abstract}

Results: In our study, out of 50 patients with abdominal Tuberculosis, 28 were males (56\%) and 22 were females (44\%) with Male: Female Ratio of 1.27:1. There was a higher prevalence of Abdominal Tuberculosis in $4^{\text {th }}$ decade (36\%) followed by $3^{\text {rd }}$ decade (24\%). The most common clinical presentation was Intestinal Obstruction in 13 patients (26\%) followed by abdominal distension in 12 patients (24\%).2\% of patients were associated with HIV co-infection, and $12 \%$ of patients were associated with Pulmonary Tuberculosis.52\% of patients underwent surgical management followed by anti-tubercular drugs, $48 \%$ cases underwent medical management(ATT). Ileo-caecal region was the most common site of involvement.

Conclusions: Abdominal Tuberculosis was predominantly seen in males. Patients in their $3^{\text {rd }} \& 4^{\text {th }}$ decade of low socio-economic group were most commonly affected. Most of patients were of primary intestinal type and in some it was secondary to pulmonary tuberculosis. Majority of patients underwent surgical management followed by anti-tubercular therapy.

Keywords: Abominal Tuberculosis, anti-tubercular therapy (ATT), HIV, Ileocaecal region, Intestinal obstruction.

\section{Introduction}

Tuberculosis is a disease caused by the bacterium Mycobacterium species which is one of the commonest diseases known to mankind. It is a well known fact that it has its reputation of being one of the greatest killer diseases. There has been a trend of increased incidence of tuberculosis in human race in the last three decades which can be partly attributed to increase in population, social deprivation and HIV infection.

The morbidity and mortality due to tuberculosis leads to a discovery of newer drugs and more emphasis on the disease. With improved socioeconomic conditions and disease diagnosis in the western countries, Tuberculosis in the western countries impose little clinical problem. But in 
most developing countries like India, it remains to be a major health hazard and major health related mortality, morbidity both physically and psychologically. As we know, Tuberculosis is one of the important gastroenterological problems in Tropics.

Gastrointestinal Tuberculosis is one of the earliest known diseases which still remain the disease with diagnostic enigma due to its perplexing protean clinical manifestations. Importance of the condition lies in the diversity of the presentations and its wide spread effects on the body. It may present as acute, subacute or chronic forms and may give rise to malabsorption, more so when associated with stricture formation.

The symptoms and signs often quite vague and laboratory investigations and radiological findings are sometimes not conclusive. There is no single feature which is diagnostic for abdominal Tuberculosis. In case of any localized involvement of the structures of the abdomen the presenting clinical picture will mimic the disease of the organ only. In various studies about abdominal tuberculosis worldwide, the results show wide range in its disparity in the nature course of disease, in its diagnosis and management. We planned a study on abdominal tuberculosis to understand the nature of disease process and to evaluate the various laboratory and radiological investigations and to study the management of disease.

\section{Aims and Objectives}

The objective of this study was to assess the prevalence of abdominal tuberculosis, age wise/ sex wise distribution, types of clinical presentations of abdominal tuberculosis in our study population. to study the incidence of abdominal tuberculosis associated with active pulmonary tuberculosis.

\section{Materials \& Methods}

Retrospective \& Prospective observational study of 50 patients who were diagnosed and admitted with abdominal tuberculosis at Rajah Muthiah Medical College \& hospital, Chidambaram between August 2013-August 2018. the study included the patients diagnosed as abdominal tuberculosis and being admitted \& treated at Rajah Muthiah Medical College \& Hospital, Chidambaram. Patients associated with abdominal malignancy were excluded.

\section{Results}

\section{Sex Distribution}

\begin{tabular}{|l|c|c|}
\hline Sex & No. Of Cases & $\%$ \\
\hline Male & 28 & 56 \\
\hline Female & 22 & 44 \\
\hline Total & 50 & 100 \\
\hline
\end{tabular}

There was a higher prevalence of abdominal tuberculosis in males compared to females with sex ratio of $1.27: 1$

\section{Age Distribution}

\begin{tabular}{|l|c|c|c|c|}
\hline Age & Male & Female & Total & $\%$ \\
\hline$<20$ & 2 & 5 & 7 & 14 \\
\hline $21-30$ & 6 & 6 & 12 & 24 \\
\hline $31-40$ & 10 & 8 & 18 & 36 \\
\hline $41-50$ & 4 & 2 & 6 & 12 \\
\hline$>50$ & 6 & 1 & 7 & 14 \\
\hline Total & 28 & 22 & 50 & 100 \\
\hline \multicolumn{5}{|c|}{ MEAN AGE } \\
\hline
\end{tabular}

There was a higher prevalence in $4^{\text {th }}$ decade followed by $3^{\text {rd }}$ decade with Mean age of 34.34.

\section{Socio-Economic Status}

\begin{tabular}{|lcc|}
\hline Socio-Economic Status & Total No .Of Patients & $\%$ \\
\hline Lower Class & 39 & $\mathbf{7 8}$ \\
\hline Middle Class & 08 & $\mathbf{1 6}$ \\
\hline High Class & 03 & $\mathbf{6}$ \\
\hline
\end{tabular}

Low socio-economic group were affected more compared to other groups.

\section{Residence}

\begin{tabular}{|lcc|} 
Residence & Total No. of Patients & $\%$ \\
\hline Rural & 41 & 82 \\
\hline Urban & 09 & 18 \\
\hline
\end{tabular}

Rural population affected more than urban population. 


\section{Clinical Presentations}

\begin{tabular}{|l|c|c|c|}
\hline S. No & Clinical Presesntaion & No. of Patients & $\%$ \\
\hline 1 & Intestinal obstruction & 13 & 26 \\
\hline 2 & Abdominal mass & 9 & 18 \\
\hline 3 & Abdominal distension & 12 & 24 \\
\hline 4 & Peritonitis & 4 & 8 \\
\hline 5 & Non specific symptoms & 12 & 24 \\
\hline
\end{tabular}

\section{Radiological Invsetigations \& Its Sensitivity}

\begin{tabular}{|l|c|c|c|c|}
\hline S. No & Radiological & No .of Patients & Positive & Sensitivity \\
\hline & Investigations & Performed & & \\
\hline 1 & X - ray Chest & 50 & 06 & $12.0 \%$ \\
\hline 2 & USG Scan & 50 & 26 & $52.0 \%$ \\
\hline 3 & CT Scan & 42 & 34 & $80.9 \%$ \\
\hline 4 & Barium meal & 4 & 3 & $75.0 \%$ \\
\hline 5 & Barium Enema & 3 & 1 & $33.3 \%$ \\
\hline
\end{tabular}

Mode of Management

\begin{tabular}{|lcc|}
\hline Mode & No. Of cases & $\%$ \\
Surgery & $\mathbf{2 6}$ & $\mathbf{5 2}$ \\
\hline Medical & 24 & 48 \\
\hline
\end{tabular}

Details of Surgical Procedures Done

\begin{tabular}{|c|c|c|c|c|}
\hline S.No & Procedure & Elective & Emergency & Total \\
\hline 1 & Right Hemicolectomy & 2 & 1 & 3 \\
\hline 2 & Laparotomy and adhesiolysis & 3 & 2 & 5 \\
\hline 3 & Laparotomy and Limited Resection & 1 & 4 & 5 \\
\hline 4 & Laparotomy \& Primary closure/Diversion ileostomy & 3 & 6 & 9 \\
\hline 5 & Laparoscopy \& Intervention(Adhesiolysis/abscess drainage) & 2 & - & 2 \\
\hline 6 & Laparotomy \& drainage & - & 2 & 2 \\
\hline 7 & Laparotomy \& Strituroplasty & - & - & - \\
\hline \multirow[t]{2}{*}{8} & Anal canal dilatation & - & - & - \\
\hline & Total & 11 & 15 & 26 \\
\hline
\end{tabular}

\section{Associations with Pulmonary Tuberculosis}

\begin{tabular}{|lcc|}
\hline Associations & Total No.Of Patients & $\%$ \\
\hline Abdominal Tuberculosis Alone & 44 & 88 \\
\hline Abdominal Tuberculosis Associated With Active Pulmonary Tuberculosis & 06 & 12 \\
\hline
\end{tabular}

\section{Associations with HIV}

HIV was positive in 1 patient, which account for $2 \%$ co-infection of HIV with abdominal Tuberculosis.

\section{Ascitic Fluid CB-NAAT/ADA Levels}

In our study Ascitic fluid CB-NAAT, ADA levels was done for $18 \&$ 32patients respectively, which showed positive in $17 \& 28$ patients respectively with sensitivity of $94 \% \& 87.5 \%$.

\section{USG Abdomen}

50 patients underwent USG evaluation and findings suggestive of abdominal tuberculosis in 26 patients $(52 \%)$. Bowel wall thickening, free peritoneal fluid, loculated collections, mesenteric lymphadenopathy were diagnostic of abdominal tuberculosis.

\section{CT/CECT Abdomen}

CT abdomen has a high sensitivity of $80.9 \%$ (34 patients positive out of 42 patients) 
Diagnostic Laparoscopy: Diagnostic laparoscopy was done in 29 patients, and were diagnostic in 27 patients with sensitivity of $93.1 \%$.

\section{Conclusion}

Abdominal tuberculosis is a diagnostic enigma due to its vague clinical presentations. The diagnosis remains inconclusive even after laboratory \& radiological evaluation. To diagnose abdominal tuberculosis -a high degree of clinical suspicion is needed.

Abdominal tuberculosis was predominantly seen in Low socio-economic group, and males were commonly affected and higher prevalence in $3^{\text {rd }} \&$ $4^{\text {th }}$ decades. Intestinal obstruction was the commonest presentation in our study. All patients with abdominal tuberculosis should be definitely screened for HIV co-infection, as tubercular infection was on the rise in immuno-compromised AIDS patients. Anti-tubercular therapy is the treatment of choice in abdominal tuberculosis, and surgery is indicated in patients with complications.

\section{References}

1. Peda Veerraju E. Abdominal tuberculosis. In: Satya Sri S, editor. Textbook of pulmonary and extrapulmonary tuberculosis. 3rd Ed. New Delhi: Interprint; 1998 p. 250-2

2. Paustian FF. Tuberculosis of the intestine. In: Bockus HL, editor. Gastroenterology, vol.11, 2nd edition.

3. Bhansali SK. Abdominal tuberculosis. Experiences with 300 cases. Am J Gastroenterol 1977; 67: 324-371.

4. Bhansali SK, Sethna JR. Intestinal obstruction: a clinical analysis of 348 cases. Indian J Surg 1970; 32: 57-70.

5. Gill, Eggleston FC. Acute intestinal obstruction. Arch Surg 1965; 91: 589-91.
6. Dwivedi M, Misra SP, Misra V, Kumar R. Value of adenosine deaminase estimation in the diagnosis of tuberculous ascites. Am J Gastroenterol 1990; 85 : 1123-5.

7. Balasubramanian $\mathrm{R}$, Ramachandran $\mathrm{R}$, Joseph PE, Nagarajan M, Thiruvengadam $\mathrm{KV}$, Tripathy SP, et al. Interim results of a clinical study of abdom inal tuberculosis. Indian J Tuberc 1989; 36 : 117-21

8. Gulati MS, Sarma D, Paul SB. CT appearances in abdominal tuberculosis. A pictorial assay. Clin Imaging 1999; 23: 519.

9. Kedar RP, Shah PP, Shivde RS, Malde HM. Sonographic findings in gastrointestinal and peritoneal tuberculosis. Clin Radiol 1994; 49 : 24-9.

10. Bhargava DK, Tandon HD, Chawla TC, Shriniwas, Tandon BN, Kapur BM. Diagnosis of ileocecal and colonic tuberculosis by colonoscopy. Gastrointest Endosc 1985; $31: 68-70$. 